\title{
Community Participation in Integrated Solid Waste Management in Legetafo-Legedadi Town, Oromia, Ethiopia
}

\author{
Mesfin Assefa*, Birhanu Girma \\ Institute of Architecture, Building Construction and City Development, Addis Ababa University, Addis Ababa, Ethiopia
}

Email address:

Mesfinassefa491@gmail.com (M. Assefa)

${ }^{*}$ Corresponding author

\section{To cite this article:}

Mesfin Assefa, Birhanu Girma. Community Participation in Integrated Solid Waste Management in Legetafo-Legedadi Town, Oromia, Ethiopia. Urban and Regional Planning. Vol. 5, No. 1, 2020, pp. 15-24. doi: 10.11648/j.urp.20200501.13

Received: December 24, 2019; Accepted: March 4, 2020; Published: March 17, 2020

\begin{abstract}
The idea and practice of Municipal Solid Waste Management is multifaceted problems that cannot be solved when solutions focuses only on technical performance, but also treated in holistic manner. Hence, the status and types of community engagement in SWM at the study area was addressed in detail as an objective of the study. The study employed descriptive survey research design using quantitative and qualitative data. It applied convenience sampling procedure. The data have been collected through key informants interview, document review, field observation, FGD and questionnaire. The data was analyzed using ordinal regression. This study reveals the following findings. The contribution of the society in different perspectives like finance, material and labor ranging in low status of $61.1 \%$, , the formal organizational structure create low status of $65.3 \%$. The capacity building and sensitization aspect accounts to $71.4 \%$ with low status in raising the society's awareness's and sensitization. Whereas, the FGD pertains that at least there were two waste campaigns at the town administration for awareness creation and cleansing. Most of the respondents accounts 217 (63.8\%) do not know the laws, regulations and directives of solid waste; and also the status of community empowerment provides $67.5 \%$ low. The formal organizational structures system, roles, and responsibilities has very low and low (65.3\%). As a result; LagaTafo LagaDadi town is characterized by poor management of solid waste and low community participation in the process. In consequence, poor SWM is becoming a major threat for health, environment and economic development of the town.
\end{abstract}

Keywords: Community Participation, Municipal Solid Waste, Integrated Solid Waste Management, Awareness Rising

\section{Introduction}

This paper presents the data collected from the respondents at the study area, Legetafo-Legedadi town administration, while the study held on; and describes its implication as researchers. In addition, the discussion session also narrates the trends of community engagement of the town. Hence, the status and types of community engagement in solid waste management at the study area were addressed in detail. The dependent variables and independent variables were treated using ordinal regression. To manage the data and provide the precise description variables ordinal regression was considered as tools of analysis.

\subsection{Overview of Community Participation in ISWM}

Community participation can comprise varying degrees of involvement of the local community. This can range from the contribution of cash and labor to consultation, adaptation of behaviour, involvement in administration, management and decision-making [15]. Furthermore, community participation in MSWM refers to a range of activities that members of a beneficiary community can do to assist in planning and/or implementing a solid waste management project The approaches of waste management attribute involvement of communities in service delivery as well as giving technical and financial supports [7].

Strong community organizations may be able to provide solid waste collection services through self-help approaches, contracting with private enterprises, or establishing collectives to perform the service. According to Oakley and Marsden, model of defining community involvement, as a means to an end and it is an end by itself. The researcher give due attention to the community involvement acts as a means to an end rather than considering it as an end and the 
community engagement in an integrated manner [13].

The idea of waste management is a complex multidimensional problem cannot solve when solutions focuses only on the technical performance problem of collection and safe disposal of urban waste. ISWM focuses on different dimensions of urban waste systems. The first dimension is the involvement and empowerment of stakeholders in the planning and execution of the waste management process; the second dimension consists of the eight waste system elements, including collection, reuse, disposal, recycling and the like. Therefore, community participation on solid waste management is effective means of addressing financial, technical and human resources related problems and have numerous benefits for municipal authorities regarding saving the cost of collection and disposal [14].

Concisely, community participation in MSWM refers to a range of activities that members of a beneficiary community can do to assist in planning and/or implementing a solid waste management project. Strong community organizations may be able to provide solid waste collection services through self-help approaches, contracting with private enterprises, or establishing collectives to perform the service. Such direct participation of the community is generally limited to activities associated with primary collection of domestic refuse.

ISWM is characterized by public and private investments that result in improved economic returns, healthy environment, and social development. A successful solid waste management plan requires a systems approach rather than fragmented individual attempts. Societies need to evaluate, in a holistic and integrated manner, the combination of components that can maximize economic, environmental and social benefits at a reasonable cost for current and future MSW generation [5].

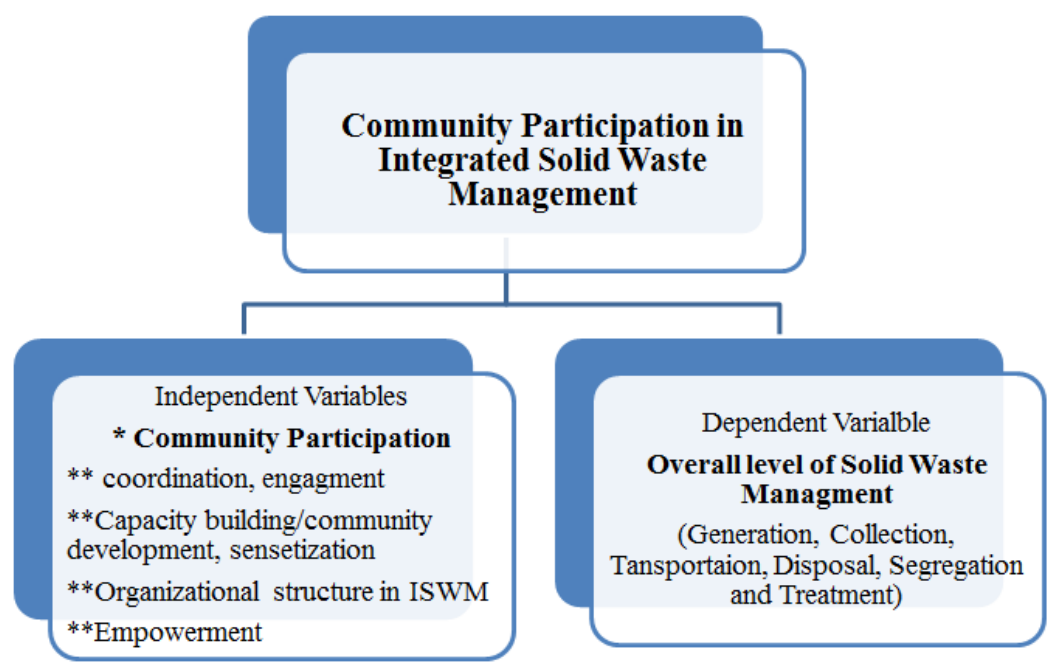

Figure 1. Independent and dependent variables relation Source: Researcher sketch.

\subsection{Problem of the Statement and Justification}

In many of the towns and cities in Ethiopia, the municipal administration is responsible for waste collection and management. Though, there is a wide variation in performance in relation to waste collection in towns and cities, it has become a common business practice to have household waste to be pre-collected by individuals who are organized through formal or informal association. The collected waste is shifted to containers, which are then collected by municipalities. This process has resulted in poor performance and consequently the disposal of waste has proved to be a major public health issue and a vital factor affecting the quality of the environment.

The emerging town of Lege-TafoLegedadi of Oromia Region faces similar situation. Today, the town faces poor solid waste management that has become one of the most intractable environmental problems. One of the main problems facing the town is open and indiscriminate dumping of refuse (author's observation). Piles of decaying garbage are found in strategic locations in the heart of the town. Wastes in such places are obviously a source of air and water pollution, land contamination and environmental degradation.

Community participation in solid waste management in the town does poorly exist. Apparently, residents are facing health and environmental challenges due to poor management of solid wastes. Absence of proper participation and involvement of the communities and the public within the solid waste management system demands the Municipalities high costs as the results of which large quantity of the generated waste is being left uncollected. Because of this challenge, a solid waste management system demands the inevitable involvement of community participation from the point of production up to the disposal site [16]. With this regards, there should be an investigation to look into the level of health problem caused by poor solid waste management. Thus, community participation in solid waste management could be sustainable solution to the problem.

Today, there is no empirical evidence that observes and clearly identifies the involvement of community in designing, implementing and evaluating strategies in solid waste management process in the town. This implies that solid waste management and community participation is least studied 
hence, it requires vigilant academic inquiry. In other words, absence of empirical researches on the assessment of solid waste management in town like Legetafo-Legedadi and the challenges the town's face necessitates the research through scientific investigation particularly focused on a selected case area that represent most emerging town in Ethiopia.

\subsection{Research Questions}

This study is intended to answer the following questions

1. What are the roles of community participation in Integrated Solid Waste Management in the study area?

2. How does currently community participate in Integrated Solid Waste Management system of the town?

3. What are the major factors that affecting community participation in Integrated Solid Waste Management system of the town?

\subsection{Research Objectives}

\subsubsection{General Objective}

The general objective of the study is to make a scientific inquiry on current community participation in solid waste management system; to devise, and develop a practical solution of an improved integrated solid waste management through community participation to the town of LageTafoLagaDadi

\subsubsection{Specific Objectives}

1. To explore the level of community participation in integrated solid waste management in the study area;

2. To examine the current practice of community participation in solid waste management system of the town;

3. To identify factors affecting community participation in the solid waste management system of the town

\subsection{Significance of the Research}

The research aspires to explore the holistic approach of solid waste management system through community participation that would be an integrated model for emerging towns or cities of Ethiopia

i. It would be significant to raise awareness of the community, private sector (public private partnership), the government and all other stakeholders to improve the management of solid waste in the town.

ii. It helps as guidelines and reference for the researchers and decision makers

\subsection{Description of Study Area}

Legetafo-Legedadi town administration is located in Oromia National Regional State, along the avenue to DessieMekele at a distance of $21 \mathrm{~km}$ from Addis Ababa, the capital city of the Ethiopia. The town surrounded by Berek woreda of special zone surrounding Finfinnee in all directions except in South West which surrounds Addis Ababa. Its astronomical location is between $9^{\circ} 01^{\prime} 29^{\prime \prime} \mathrm{N}-9^{\circ} 06^{\prime} 0^{\prime \prime}$ North

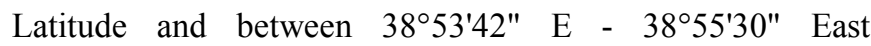
Longitude. It is located at altitude 2,316 to 2,500 masl. The mean annual, maximum and minimum temperatures of the town are calculated to $17.22^{\circ} \mathrm{C}, 23.76^{\circ} \mathrm{C} \& 10.67^{\circ} \mathrm{C}$, respectively, which is the characteristic of a warm temperate climate [11]. Recently the town administration has four kebeles namely, LagaTafo (01) and LagaDadi (02), Dambel and Eka Sadden with in an area of 24,350 hectares. According Oromia Urban Planning Institute, 2016, the town had a population of 52054 .

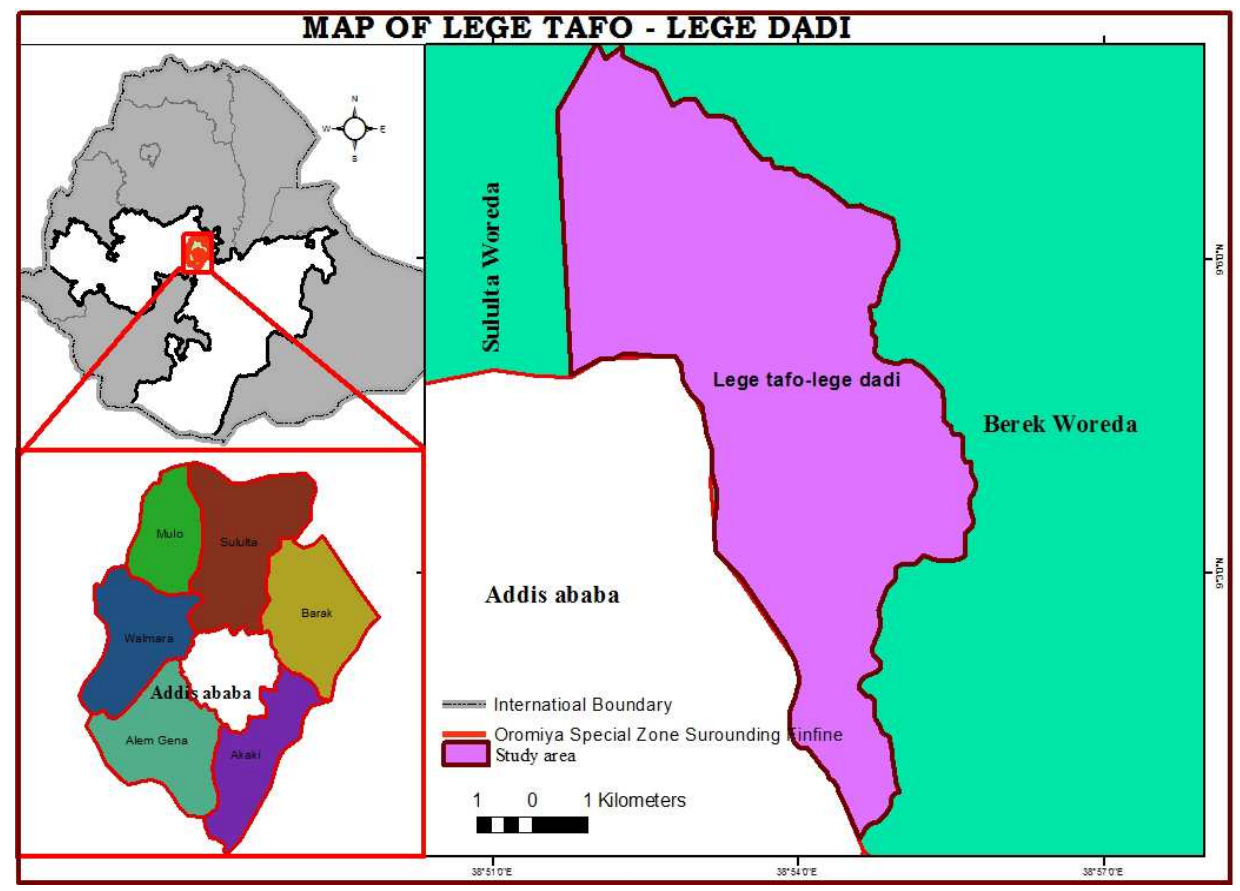

Sources; Mesfin and Mukter, 2016

Figure 2. Location Map of Legetafo-Legedadi town. 


\section{Methodology}

\subsection{Research Approach}

The research applied both quantitative and qualitative research approaches. These help the use of a broad spectrum of quantitative and qualitative approaches in order to gather and analyze data.

\subsection{Research Design}

The research employed descriptive survey research design that helps to "describe phenomena accurately", not only using quantitative data but also qualitative data. This design also corresponds to Cross-sectional research design that aims at getting data from multiple cases at a given point in time to analyze relationships across a number of variables of interest [4].

\subsection{Data Sources and Types}

The data sources for the research were from both primary and secondary sources. The primary data was collected from households, key informants, focus group discussion of the participants, and concerned government officials at different levels. The data were supported by the direct observation of the researcher to the study sites. In utilizing secondary sources, published articles, research works, previous studies, books, government reports from the federal and regional offices, municipal administration offices, and Central Statistical Agency and other sources were reviewed. In addition to this, both qualitative and quantitative data have been collected through data collection instruments used for the research.

\subsection{Data Collection Tools}

To collect data the study used key informant interview, document review, observation, Focus Group Discussions, questionnaire and non-participatory observations. Depending on the kind of data, the researcher used the most appropriate data collection method to get the data from the different respondents.

\subsubsection{Document Reviews}

Documents obtained from the municipality regarding solid waste management were reviewed. The basic points identified from the reviews were used as inputs to consolidate the findings of the study.

\subsubsection{Interviews}

Key informant interviews were conducted among four coordinators and four experts from solid waste management in the municipality and Kebele levels. The main instrument used to interview key informants was a semi-structured interview, which contained open-ended questions.

\subsubsection{Focus Group Discussions}

To use the social dynamics of the group and to collect essential information about their opinions, experience, perception, beliefs, and attitude on solid waste management four focus group discussions have been conducted, each of which consisting of 15- 20 members, were purposively selected from households from all four Kebeles by taking into account sexes, various ranges of age, and occupations.

\subsection{Sampling}

\subsubsection{Sample Size Determination}

The sample size determination process was conducted using two sample size determination formulas. The study also considered households living in the town as the primary source of information for the survey research. Therefore, the population frame is 10411 households who have been living in the town. In determining the representative sample size for the study, the researcher has used two category of sampling formulas.

The first formula, which is used in the study, is the one proposed by Krejcie and Morgan [9] for determining needed sample size in research when the population is known. The formula is stated as:

$$
S=\frac{X^{2} N P(1-P)}{D^{2}(N-1)+X^{2} P(1-p)}
$$

Where: $S=$ required sample size; $X^{2}=$ the table value of chi-square for 1 degree of freedom at 0.05 confidence level (3.841); $\mathrm{N}=$ the population size; $\mathrm{P}=$ the population proportion (assumed to be 0.50 as this would provide the maximum sample size); and $d=$ the degree of accuracy expressed as a proportion (.05).

Accordingly, using the above sampling formula, around 368 households are selected as the representative of the population. However, as there is a need to manage the sample size is representative of the population, additional sampling formulas is required to be applied in the study. Accordingly, the second formula considered in the study is the one proposed by Cochran (1977) as a finite population correction to determine the final sample that turns out to be $5 \%$ or more of the total population. The formula can be stated as:

$$
n 1=\frac{S}{1+\frac{S}{N}}
$$

Where: $\mathrm{S}=$ is desired sample size; $\mathrm{n} 1=$ is the new value for the sample size adjusted using Cochran's population correction formula; $\mathrm{N}=$ is the total number of the population from which ' $n$ ' is being drawn.

In this case, applying, the formula around 348 households selected as sample that turns out to be $5 \%$ or more of the total population. Finally, the following formula used to adjust the sample size for non-response rate.

$$
\text { Final sample size }=\frac{\text { Effective sample }}{1-\text { non-response rate anticipated }}=\frac{348}{1-10 \%}=384
$$


Accordingly, using the formula considered appropriate for this study, around 384 respondents drawn proportionally for both residential households and non-residential entities of Kebeles of the town. In addition, 35 CC, 5 government institutions and 5 health facilities (health center and clinics) samples were investigated. Such limited samples used due to financial, time and effort constraints.

\subsubsection{Sampling Procedure}

The four kebeles of the town administration were totally sampled using purposive techniques. This helps the researcher to assess the opinion of residents living in different kebeles, having varies demographic characteristics like occupation, income, \&etc. and also to consider the local, community neighborhood, and other organizational structure solid waste management. The procedure of reaching the individual respondents or households selected for sampling based on convenience sampling technique. It was not deem viable to choose the sample by random sampling, because the town administration did not have population and households' database or list of all the residents, traders and market venders. Hence, the researcher had selected four influential residents with additional four expertise of the town administration to fill questionnaire through convenience sampling method.

\section{Results and Discussion}

\subsection{Community Involvement}

The cooperation of households in collaborative way for different contribution resulted in $379(27.6 \%)$ very low, 459 (33.5\%) low, 334 (24.3\%) medium, 139 (10.1\%) high, 61 $(4.4 \%)$ very high. It indicates that the contribution of the society in different perspectives like finance, material and labor ranging in low and very low status which accounts about $61.1 \%$. Lack of awareness and active public involvement within the solid waste management system makes the solid collection and transportation ineffective in Ethiopian urban centers [8]. This motivates public to haphazard handling and disposal of waste in any open spaces as well as riverbanks, and ditches that in turn becomes a causative agent for environment pollution and widespread of various contagious diseases. The community participation was low in collective action forms. Participating in campaign or other cooperation with other waste actors need cultural grounds and policy oriented [2].

Although waste management responsibilities primarily lie with cities and municipalities, many of the successful cases in waste management involve a wide range of stakeholders in their implementation. The key to success is to do what they are good at, and collaborate with other sectors in the society, such as private sector, and communities [11]. Other study Kaduna metropolis about the nature of community contributions revealed that $15.9 \%$ not necessary to engage in it, $20.1 \%$ households can participate by paying, $46.9 \%$ participation within the process or system [16]. However, in Legetafo-Legedadi town administration context the community engagement was low, even though they are both the major stakeholders and beneficiaries for or from the activities.

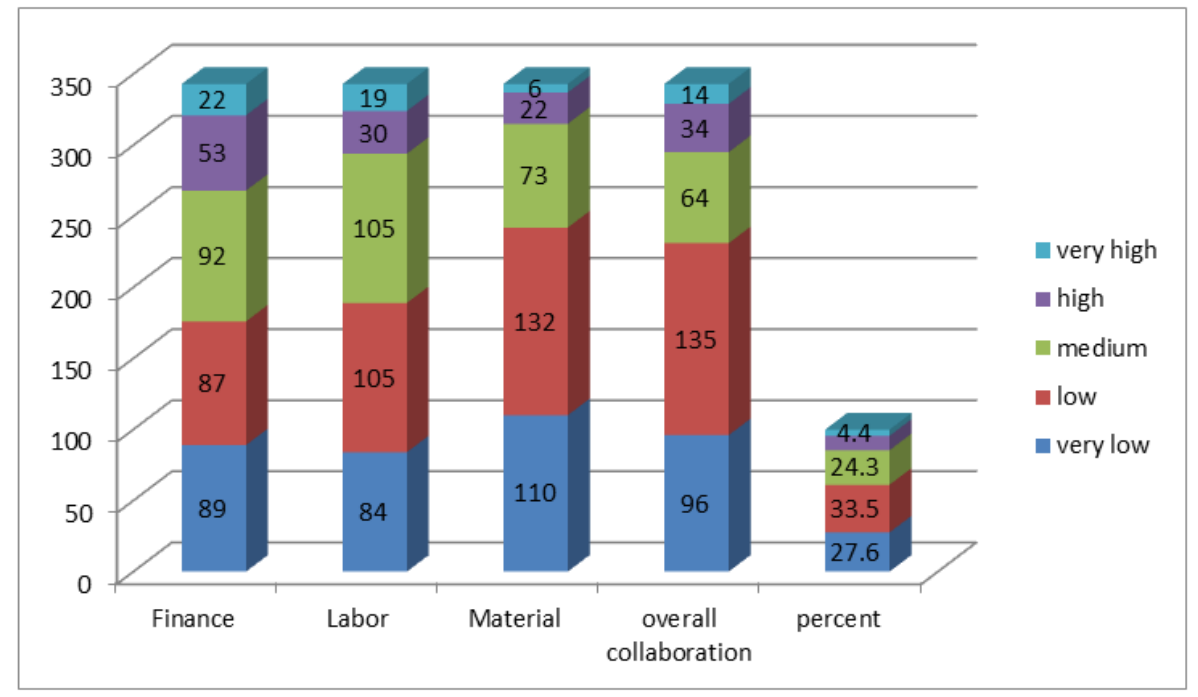

Figure 3. Community involvements on financial, material and labor resources.

\subsection{Capacity Building and Sensitization}

Figure 5 reveals that $38.6 \%$ (662) very low, 32.8\% (563) low, 19.4\% (334) medium, 6.8\% (117) high, and 2.3\% (39) very high status in capacity building and sensitization of the neighborhood communities. The data indicates that the development team of the local or neighborhood communities, the local authorities and other stakeholders create very low and low which contributes about $71.4 \%$ in raising the society's awareness's and sensitization.

To the contrary, the focus group discussion held with the expertise and heads of different sectors justified that the municipality, has been conducted a solid waste disposal campaign with the employees of different sectors twice a year during the winter or 'kiremt' (sene, hamile and nehase 
(June, July August) months and spring 'tsedey' (Meskerem, tikimit and hidar (September, October and December) months. These two seasons selected because in summer (kiremt) season solid wastes dispose and block the drainages and the passing of summer season and deposition of solid wastes at different places. In these campaigns cleaning the drainages, main streets, market places, and erosion dumped areas; as well as creating mobilization and society awareness's have taken place. In addition, the key informants provide that the sensitization and promotion of the neighborhood and active participant stakeholders on integrated solid waste management remain behind.

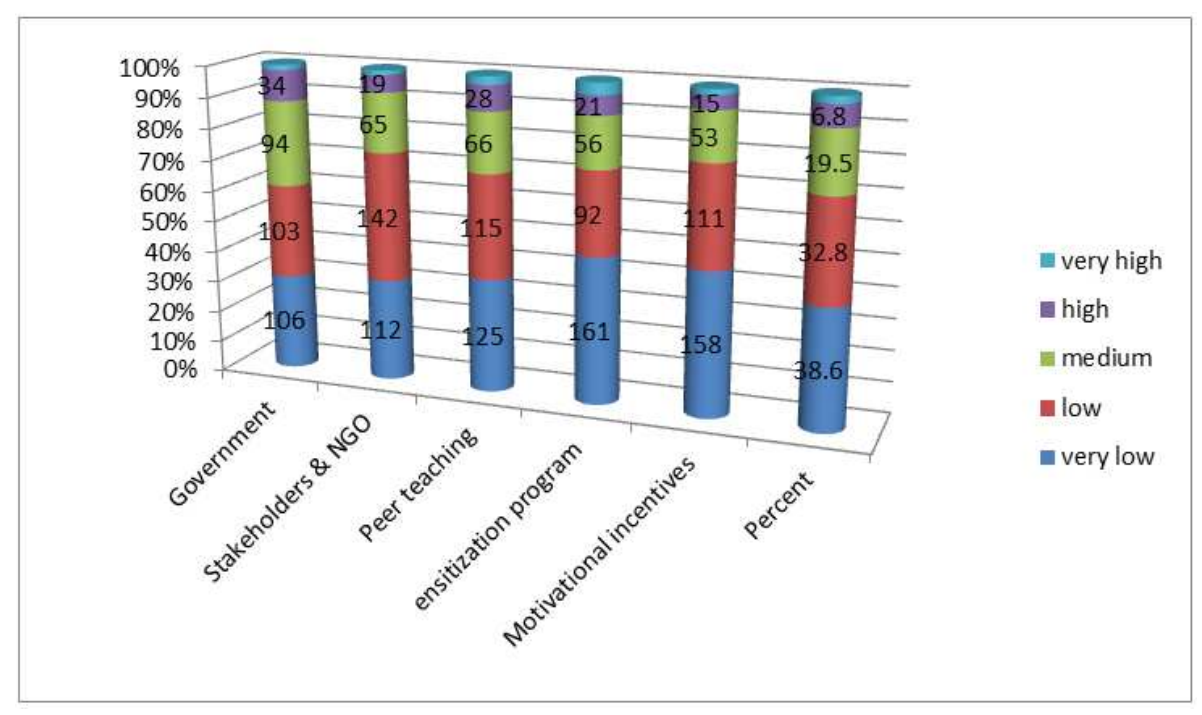

Figure 4. Status of capacity building and sensitization in different kinds.

Raising awareness and sensitization through instruction, education, promotion and communication programs work best when they are coordinated with actual planning and implementation of new approaches in waste management. The local authorities, political or social leaders, religious leaders, and school teachers can play an important role in stimulating the desired behavior [12]. Neighbors and street committees create agreement among themselves about good practices in their homes and area. They admonish each other and develop understanding of the difficulties involved.

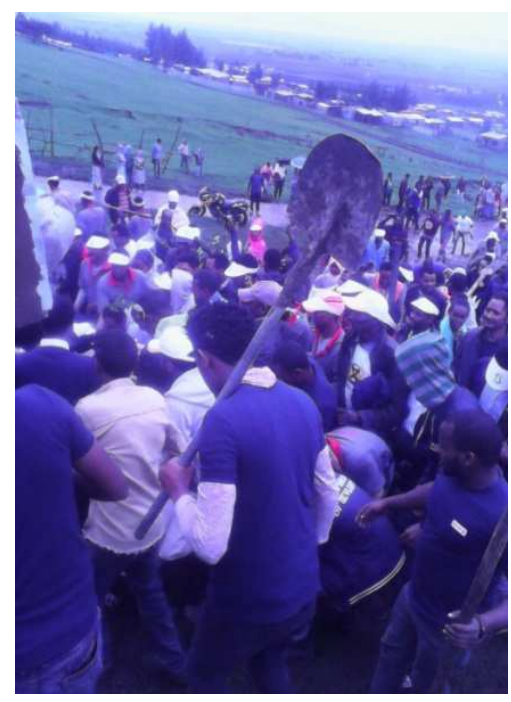

Source: Researcher field observation

Figure 5. The Employees campaign on Solid Waste twice a year.

Moreover, the society accustomed that with their home, households and neighborhood level they burn, collect, dispose, and clean the solid waste on November 22 (Hidar 12) per annum. There is a proverb said by the society 'Hidarsitaten', which relates to the tale, during early time there were diseases transmitted due to hygiene problem. As a result many Ethiopian died, consequently the fumigation has been conducted in the month of November 'Hidar' throughout the country then disease had been stopped. The same practice has been going on Legetafo-Legedadi town by the societies. Sensitivity and awareness campaigns are also very important in combating cultural taboos and prejudices about waste and those who work in, on and with it [12].

Awareness raising and mobilization methods include clean up campaigns in schools, markets and other public places as well as in the neighborhoods, the drainage canals. Moreover, different communication mechanisms like presentations, inclusion of waste management in school curriculum, school playwriting contests on the theme of urban sanitation, local $\mathrm{TV}$ and radio station programs produced the best play on environmental sanitation, neighborhood group meetings for men and women and other too [12].

\subsection{Formal Organizational Structure}

Table 1 show that $31.6 \%$ (325) very low, 33.7\% (347) low, $22.6 \%$ (233) medium, and $8.6 \%$ (88) high and 3.5\% (36) very high rate in the existence of formal organization and roles and responsibilities about different stakeholder's participation in solid waste management. Conversely, the secondary data indicated that local institution coherence was existing local institution coherence from organizational structure to inter-municipal relation with rating value of $50 \%$ 
out of $100 \%$. In addition, while the researcher conducted the field observation and secondary data assessment, it showed the existence of the organizational structure in the town administration but it is non-functional. Besides, the focus group discussion and key informants provide that there is formal organization begins from the community or neighborhood development team, kebele, and town administration. The key informants justify that the society may not clearly know the formal structure for the development or the formal structure may not function at their level, and hence they consider as if it is not presenting.

Table 1. The Existence of formal structure.

\begin{tabular}{|c|c|c|c|c|c|c|c|}
\hline No & Items & Very low & low & medium & high & very high & Total \\
\hline 1 & There is a structure organized for ISWM within the society & 114 & 126 & 74 & 18 & 11 & 343 \\
\hline 2 & $\begin{array}{l}\text { The organized structure has roles and responsibilities for each } \\
\text { individuals and households }\end{array}$ & 118 & 124 & 72 & 19 & 10 & 343 \\
\hline \multirow[t]{3}{*}{3} & There is an organization of capable SME for ISWM & 93 & 97 & 87 & 51 & 15 & 343 \\
\hline & Total & 325 & 347 & 233 & 88 & 36 & 1029 \\
\hline & $\%$ & 31.6 & 33.72 & 22.64334 & 8.55 & 3.499 & 100 \\
\hline
\end{tabular}

Urban managers are therefore encouraged to pursue the paths of Integrated Solid Waste Management (ISWM) and Reduce, Reuse and Recycle (3Rs) that place highest priority on waste prevention, waste reduction, and waste recycling instead of just trying to cope with ever-increasing amounts of waste through treatment and disposal. Such efforts will help cities to reduce the financial burden on town authorities for waste management, as well as reduce the pressure on landfill requirements [12].

\subsection{Empowerment}

The society empowerment from problem identification, planning, implementation, decision-making and evaluation up on solid waste management data presents the following. The data reveals that $31.9 \%$ very low, $35.6 \%$ low, $19.9 \%$ medium, $9.0 \%$ high and $3.6 \%$ very high. It indicates that the community empowerment in integrated solid waste management was very low and low which accounts $67.5 \%$.

Table 2. Community empowerment in an integrated solid management.

\begin{tabular}{|c|c|c|c|c|c|c|c|}
\hline No & Items & Very low & low & medium & high & very high & Total N \\
\hline 1 & The households participate the ISWM annual planning management & 118 & 104 & 74 & 37 & 10 & 343 \\
\hline 2 & The households participate the ISWM in decision making & 112 & 110 & 72 & 35 & 14 & 343 \\
\hline 3 & The society participate for ISWM of the town administration actively & 102 & 131 & 66 & 31 & 13 & 343 \\
\hline 4 & The society empowered for the process of IWSM & 111 & 135 & 62 & 27 & 8 & 343 \\
\hline 5 & The community participate in problem solving or trouble-shooting & 89 & 122 & 85 & 30 & 17 & 343 \\
\hline \multirow[t]{2}{*}{6} & The community monitors and evaluate the progress & 124 & 130 & 50 & 26 & 13 & 343 \\
\hline & $\%$ & 31.9 & 35.57 & 19.87366 & 9.04 & 3.644 & 100 \\
\hline
\end{tabular}

\subsection{Awareness About the Laws Enacted}

The question asked, "Is there any proclamations, rule, regulation and directives enacted for Municipal ISWM?" responded that:

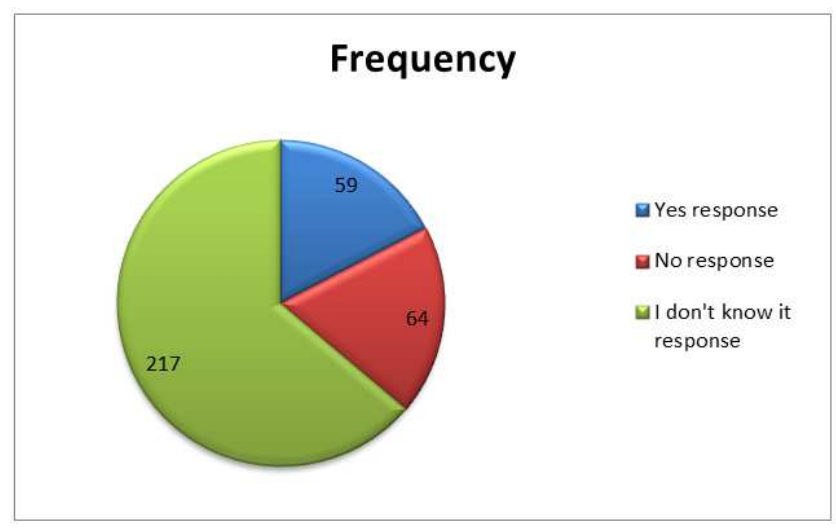

Figure 6. Community awareness about the Proclamations, regulation and laws in general enacted on ISWM.
Figure 6 depicts that $59(17.4 \%)$ of the respondents reacted that they know the laws enacted, $64(18.8 \%)$ reacted that there is no laws enacted for municipal ISWM, surprisingly $217(63.8 \%)$ responded that they do not have any information about the laws. Regarding public awareness about laws and regulations of solid waste management, only $24 \%$ of respondents indicated they were aware about waste laws and regulations. Almost two thirds of respondents did not have awareness about this issue [2]. The secondary data also makes public that Legetafo-Legedadi town administration council reviewing and adapting the refuse of solid waste and sanitary by-law since 2013 , in line with the integrated waste management plan for the town. This notice addresses illegal dumping and sanitation related problems and penalties thereof in open places within residential, farm, and open space areas. The law the national and international laws, proclamations and regulations. 


\subsection{Participation at Household Level}

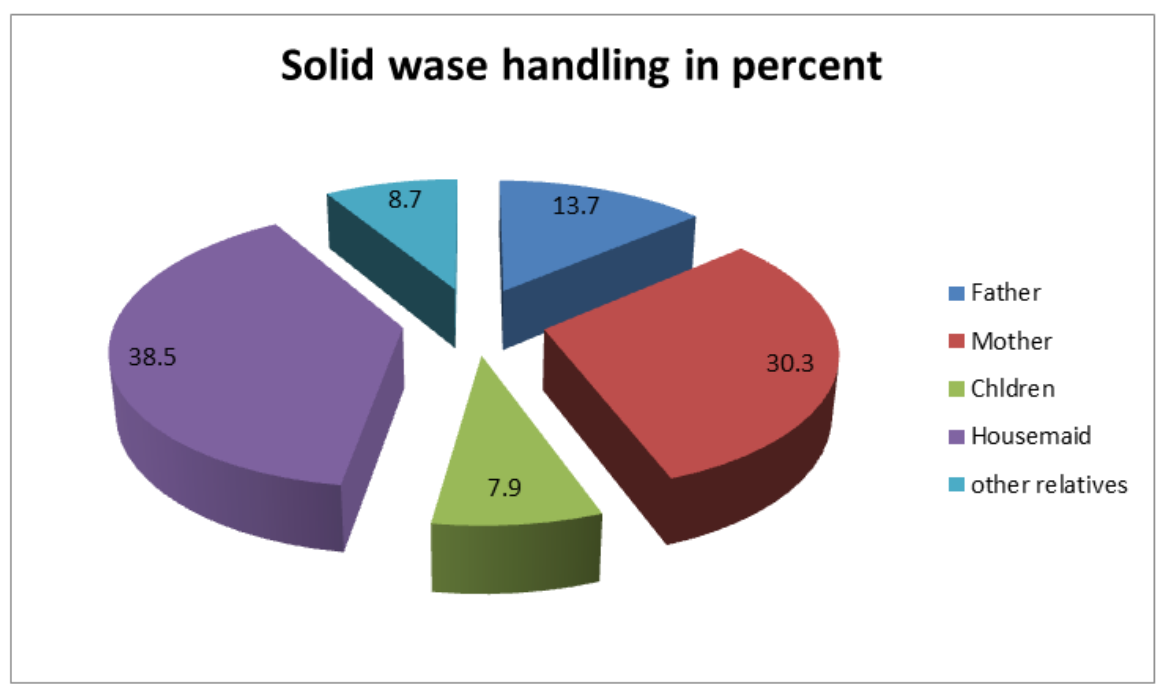

Figure 7. Solid waste handling data at household level.

In figure 7 the respondents' data shows that the housemaid (38.5\%), mother $(30.3 \%)$, father $(13.7 \%)$, children $(7.9 \%)$ and other relatives $(8.7 \%)$. The housemaid and mother hold more responsibility than other family members which encountered $68.8 \%$ at the house level for reducing, collecting and separating. The role of women in waste management and promotion of sustainable development is so pivotal. It is quite evident that they are directly concerned with waste management at home [1].

In many respects, the household is the most important and smallest economic unit in an urban environment. Women are the household managers and the members of the household often having the principal responsibility for managing the practical aspects of daily life, such as getting and preparing food, supplying water, assuring cleanliness, and maintaining the physical spaces. Because women are charged with the responsibility for cleanliness of the home and for the health of the family, they can be viewed as the solid waste managers of the household (Bernstein, 2004). Moreover, Bernstein (2004) emphasized that women are primarily responsible for managing household work and for the socialization of children in a family; it is most effective to target environmental education on waste management to women rather than men.

The gender aspects of decision-making within households and within the community about the organization of collection, re-use, recycling, disposal of waste cannot be ignored. In fact, when there are problems with service provision, a practical step is to talk with the women to understand the causes of the problems. Information may have been collected from one sex probably men when women have more accurate information [11].

\subsection{Overall Status of the ISWM}

Table 3. The overall status of SWM in an integrated manner with community participation.

\begin{tabular}{|c|c|c|c|c|c|}
\hline \multicolumn{6}{|c|}{ How do you measure the overall status of SWM in integrated manner with community participation } \\
\hline & & Frequency & Percent & Valid Percent & Cumulative Percent \\
\hline \multirow{5}{*}{ Valid } & Very low & 86 & 23.5 & 24.2 & 24.2 \\
\hline & Low & 194 & 53.0 & 54.5 & 78.7 \\
\hline & medium & 65 & 17.8 & 18.3 & 96.9 \\
\hline & High & 11 & 3.0 & 3.1 & 100.0 \\
\hline & Total & 356 & 97.3 & 100.0 & \\
\hline Missing & System & 10 & 2.7 & & \\
\hline Total & & 366 & 100.0 & & \\
\hline
\end{tabular}

Table 3 depicts that the respondents rate the overall status of the community participation based on the item which is "How do you measure the overall status of SWM in an integrated manner with community participation?". They reacts that $53.0 \%$ (194) low, $23.5 \%$ (86) very low, $17.8 \%$ (65) medium, $3.0 \%$ (11) high and none of them said the status was very high. It indicates that more than $3 / 4(75 \%)$ of the respondents replied that the overall status of SWM in an integrated manner at Legetafo-Legedadi town administration was low and very low, which is below an average. The secondary data from the team evaluation report that the community participation and the overall integrated solid waste management in Legetafo-Legedadi town administration was $47 \%$, which indicates it is low status. 
Therefore, the society do not satisfied with the service earned from the solid waste management through community participation in an integrated manner.

In many towns and cities of developing countries where some private sector and communities are engaging in some segments of solid waste management system still it is very limited [11].

\section{Factors Affecting Community Participation in Integrated Solid Waste Management in Legetafo-Legedadi Town}

Interview with key informants' and the focus group discussions held in the town revealed that the community participation in solid waste management is limited because of institutional, socio-cultural, and financial related matters such as the absence of collection facilities and infrastructures, incentives to solid waste collectors, inadequate assignment of budget to the sanitation, illegal waste disposal for fear of the costs incurred for collection services to the Micro Small Enterprises.

The poor infrastructure and equipment, management arrangements that have not adequately coordinated the interventions of the different actors, inefficient collection, and management of the refuse collection charges, absence of solid waste collection points, and lack of a proper landfill, among others, are the factors affecting community participation in solid waste management system.

The Municipality does not build institutional capacity to participate and involve in the private sectors, NGOs, CBOs, informal sectors (such as Koralios), and organizations to contribute their parts in the town solid waste management system.

Other important aspects that affect the participation of the households are level of education and income. More educated and better income-earning households have a better participation role in the solid waste management system. Awareness and attitude are also other factors affecting the solid waste management system of the town.

\section{Conclusions and Recommendations}

\subsection{Conclusions}

The rationale of effective community participation have been clearly based on the idea that everyone generates waste and can be affected directly and indirectly if waste is not well managed. However, the finding of this study reveals contribution of the society in different perspectives like finance, material and labor ranging in low status of $61.1 \%$, the formal organizational structure create low status of $65.3 \%$. The capacity building and sensitization aspect accounts to $71.4 \%$ with low status in raising the society's awareness's and sensitization. Whereas, the FGD pertains that at least there are two wastes cleansing campaigns at the town administration for awareness creation and cleansing. We can infer from this, Community's participation and involvement is limited to household level waste collection and cleansing campaign. Most of the respondents accounts $217(63.8 \%)$ do not know the laws, regulations and directives of solid waste; and also the status of community empowerment provides $67.5 \%$ low. The formal organizational structures system, roles, and responsibilities have very low and low $(65.3 \%)$.

Factors such as lack of leadership commitment; institutional, socio-cultural, and financial related matters; poor infrastructure and equipment; management arrangements; lack of institutional capacity; the level of education; income; and awareness and attitude are found to be deterring factors to improve the solid waste management in LagatafoLagadai town.

\subsection{Recommendation}

Consistent awareness creation programs in the community to improve their involvement and participation in the solid waste management system should be given. Communities and organizations should be involved starting from identifying solid waste-related problems through planning and implementation phases in the budget year of the Municipality. This makes the community and organizations develop a sense of ownership, sharing the financial burden of the Municipality, provision of facilities and equipment needed for solid waste collection services.

Community participation is very crucial for effective and efficient maneuver of solid waste management system. Therefore, a consistent and ongoing educational program is necessary for the success of the waste management system in Legetafo-Legedadi town.

\section{References}

[1] Adum, A. E. (2013). Bottom-Up Approach to Sustainable Solid Waste Management in African Countries. Germany: Brandenburg Univesity of Technology, Cottubus.

[2] Ahmadi, M., Mohammed, A. F., \& Kamali, M. (2016). Sustainable Municipal Waste Management Improvement in Tehran Town through Community Participation. International Journal of Waste Resources Volume 6, No. 247, Issue 3; doi: 10.4172/2252-5211.1000247, 1-5.

[3] Bryman, A. (2004). Social Research Methods. Oxford: Oxford University Press

[4] Creswell, John W. (2012). Educational research: Planning, conducting and evaluating quantitative and qualitative research. Fourth Edition. Boston, MA: Pearson Education, Inc.

[5] Elagroudy, S., Warith, M. A., \& Zayat, M. E. (2016). Municipal Solid Waste Management and Green Economy. Berlin: Global Young Academy.

[6] Finn, K. R. (2007). A Study of the Households' Willingness to Contribute to an Improved Solid Waste Managment Progrma in Kratovo Macedonia. Michigan Technology University. 
[7] Rangeti I, Tendere T, Guzha E and Gwisai RD (2018) Community Participation, the Missing Link towards Sustainable Solid Waste Management: Lessons from Bindura Town, Zimbabwe. Greener Journal of Social Sciences, 8 (2): 018- 028, http://doi.org/10.15580/GJSS.2018.2.050516085.

[8] Hayal Desta, Hailu Worku and Aramde Fetene. (2014). Assessment of the Contemporary Municipal Solid Waste Management in Urban Environment: The Case of Addis Ababa,

[9] Krejcie, R. V., \& Morgan, D. W. (1970). Determining Sample Size for Research Activities. Educational and Psychological Measurement, 30, 607-610 Ethiopia. Journal of Environmental Science and Technology, 7, 107-122.

[10] Mesfin Assefa, Muktar Mohammed. Solid Waste Generation Rate and Characterization Study for Legetafo-Legedadi Town, Oromia, Ethiopia. International Journal of Environmental Protection and Policy. Vol. 5, No. 6, 2017, pp. 84-93. doi: 10.11648/j.ijepp.20170506.11

[11] Modak, P. (2016). Municcipal Solid Waste Management: A Guide for Sustainable Urban Development in the 21st Century. Shanghai.
[12] Muller, M., \& Hoffman, L. (2001). Community Partnerships in Integrated Sustainable Waste Management: Tools for Decision makers experiences from the Urban Waste Expertise Progamme (1995-2001). Nieuwehaven 201, Netherlands: WASTE.

[13] Oakely and Marsden (1984). Approaches to participation in rural development. International Labour Office, Geneva, Swizerland.

[14] Tracey J. M. McKay, John Tambe-Ddip Mbanda, Michelle Lawton. (2015) Exploring the challenges facing the solid waste sector in Douala, Cameroon. Department of Environmental Science, University of South Africa.

[15] Tukahirwa (2010). Civil society participation in urban sanitation and solid waste management in Uganda; The International Journal of Justice and SustainabilityVolume 15, 2010 - Issue.

[16] Yakubu, K., \& Mado, H. (2018). Assessment of Community Participation in Solid Waste Management in Kaduna Metropolis. ResearchGate, Research Gate. 